\title{
PhiMiSci
}

Philosophy and the Mind Sciences

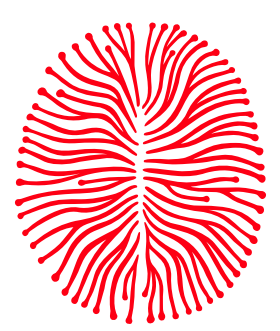

\section{Is mental time travel real time travel?}

\author{
Michael Barkasi ${ }^{\mathrm{a}}$ (D) (michael.barkasi@gmail.com) \\ Melanie G. Rosen ${ }^{\mathrm{b}}$ (D) (melanie.rosen@gmail.com)
}

\begin{abstract}
Episodic memory (memories of the personal past) and prospecting the future (anticipating events) are often described as mental time travel (MTT). While most use this description metaphorically, we argue that episodic memory may allow for MTT in at least some robust sense. While episodic memory experiences may not allow us to literally travel through time, they do afford genuine awareness of past-perceived events. This is in contrast to an alternative view on which episodic memory experiences present past-perceived events as mere intentional contents. Hence, episodic memory is a way of coming into experiential contact with, or being again aware of, what happened in the past. We argue that episodic memory experiences depend on a causal-informational link with the past events being remembered, and that, assuming direct realism about episodic memory experiences, this link suffices for genuine awareness. Since there is no such link in future prospection, a similar argument cannot be used to show that it also affords genuine awareness of future events. Constructivist views of memory might challenge the idea of memory as genuine awareness of remembered events. We explain how our view is consistent with both constructivist and anti-causalist conceptions of memory. There is still room for an interpretation of episodic memory as enabling genuine awareness of past events, even if it involves reconstruction.
\end{abstract}

\section{Keywords}

Episodic memory $\cdot$ Mental time travel $\cdot$ Perceptual experience $\cdot$ Causal theory of memory $\cdot$ Objects of memory

\section{In what sense is there mental time travel?}

Going back to his book Elements of Episodic Memory (1983), Endel Tulving describes episodic memory as enabling mental time travel. In a more recent article, he says "When one thinks today about what one did yesterday, time's arrow is bent into a loop. The rememberer has mentally traveled back into her past" (2002, p. 2). This colorful way of describing episodic memory has been widely adopted by both scientists (e.g. Beaty, Seli, \& Schacter, 2019) and philosophers (e.g. Michaelian, 2016b). Tulving is well aware that mental time travel does not really bend time's arrow: "An event happens [...] memory traces are laid down [...]. The memory

${ }^{a}$ University of Toronto Mississauga

${ }^{\mathrm{b}}$ Aarhus University 
traces [...] are retrieved, and the person remembers the event. [...] There is certainly no violation of any law of time" (Tulving, 2002, p. 19). This suggests that talk of mental time travel (hereafter 'MTT') is just a catchy metaphor for an otherwise straightforward psychological mechanism. ${ }^{1}$ Both scientists (Suddendorf \& Corballis, 2007) and philosophers (Byrne, 2010; Debus, 2014; Matthen, 2010) have taken it this way. While MTT certainly is not literal time travel, we shall argue here that it is more than mere metaphor.

The neuro-cognitive system behind episodic memory is generally taken to facilitate not only past recall but also prospecting the future (Beaty et al., 2019; Buckner \& Carroll, 2007; Schacter \& Addis, 2007; Suddendorf \& Corballis, 2007; Tulving, 2002), imagining counterfactual ways the past could have gone (De Brigard, 2014), and other forms of episodic simulation (Michaelian, 2016b ch. 6). Thus, we should not talk about a dedicated episodic memory system, but a more general episodic cognition system (Michaelian, 2016b, p. 105). Focusing on past recall and future prospection, Tulving (2002, p. 20) has bundled all the activities of this episodic cognition system under the MTT label, saying that "mental time travel involves awareness not only of what has been but also of what may come". Others use the term in the same way. For example, De Brigard (2014, p. 174) says MTT refers "to our psychological ability to mentally travel back in time [...] and to project ourselves onto the future". Suddendorf and Corballis (2007, p. 299) say MTT refers "to the faculty that allows humans to mentally project themselves backwards in time to re-live, or forwards to pre-live, events". Michaelian (2016b, p. 98) says MTT "can be directed both at the personal past and the personal future". These theorists use the term 'mental time travel' to refer to whatever people are doing as they recall the past, imagine the future, and engage in other forms of episodic cognition.

There is nothing wrong with a catchy, metaphorical term like 'mental time travel.' ${ }^{2}$ Still, we will articulate an interesting and controversial way in which episodic memory actually affords something like MTT in a non-metaphorical sense. On this notion, an experience involves (something like) MTT if it not only presents some event outside the present as a merely intentional content but also affords its subject genuine awareness of that event. On this notion, the episodic cognition system would enable MTT if the "re-experiencing" (Tulving, 2002, p. 6) of a past event, or "pre-experiencing” (Michaelian, 2016b, p. 98) of a future event, involved genuine awareness of the recalled or prospected event itself. It will take some work to explain precisely what is meant by 'genuine awareness', but if past recall or future prospection involve genuine awareness of the recalled or prospected event itself, then the subject of the recall or prospection experience is in a special sort of contact with that event. The event is "brought into consciousness", as we might

\footnotetext{
${ }^{1}$ Throughout this paper we adopt the philosophical convention of using single quotes to mention a term. We use double quotes for direct quotations of other texts and as scare quotes.

${ }^{2}$ Debus (2014, p. 335) suggests that the point of this terminology within psychology is to emphasize the underlying psychological and neurobiological similarities between past recall, future prospection, and other forms of episodic simulation.
} 
put it. So, while MTT (in this sense) does not involve the literal transposition of your physical body to spacetimes outside the present, it does involve bringing "into mind" events outside the present.

With this substantive notion of MTT in hand, it becomes an open question whether either past recall or future prospection amount to MTT. It is helpful to distinguish between the episodic cognition system - the set of neural mechanisms and the computations they implement - and the abilities and mental states it enables. It is possible that some, but not all, of these states count as MTT in our substantive sense. Thus, the question is not whether the episodic cognition system enables MTT, broadly speaking, but which, if any, of the states it enables count as MTT.

We argue that the past recall enabled by the episodic cognition system is, in fact, MTT in our sense, but that the future prospection enabled by the system is not. Specially, we shall argue that episodic memory experiences (recall experiences, for short) involve genuine awareness of the past-perceived events being remembered, while prospection experiences present imagined future events as mere intentional contents. The argument turns on the neurobiology of memory as involving memory traces which provide a causal-informational link to the past recalled events; the lack of such links in future prospection is what keeps it from also being MTT. So, the episodic cognition system enables MTT in one direction (past) but not the other (future), because only its past-directed states make contact with events outside the present.

In the following, section 2 lays out three possible ways to understand the claim that episodic cognition enables MTT. These are uninteresting, as nearly everyone will accept these senses of MTT. Section 3 articulates the notion of MTT as genuine awareness and explains how it involves bringing events outside the present into consciousness. After the main argument from causal-informational links in section 4, sections 5-7 consider to what extent the constructive nature of the episodic cognition system undercuts the case for past recall involving genuine awareness.

\section{Three preliminary notions of MTT}

Applying standard concepts from the philosophy of mind, we get three preliminary notions of MTT:

1. MTT as representation of the past/future: The claim that the episodic cognition system enables MTT could be a claim about the representational content of the states we are in as we recall the past or prospect the future. According to this claim, the accuracy of your current recalled memory or future prospection is determined by comparing what it represents to some past or future episode. In this sense, episodic cognition would enable MTT if it enabled representing something as outside the present. 
2. MTT as phenomenal similarity with past/future experiences: The claim that the episodic cognition system enables MTT could be a claim about the phenomenology of the states we are in as we recall the past or prospect the future. According to this claim, what it is like (Nagel, 1974) to remember some episode from the past or imagine oneself in the future is the same as (or matches in some key respects) what that episode was initially, or will be, like for you. In this sense, episodic cognition would enable MTT if it enabled repeating (or repeating in relevant respects) some past experience or preempting a future one. ${ }^{3}$

3. MTT as the lack of phenomenal presence: The claim that the episodic cognition system enables MTT could be a claim about the lack of phenomenal presence felt towards what is experienced as we recall the past and prospect the future. According to this claim, the phenomenology of these states is such that you experience the recalled or prospected events not as present here and now, but as past or future in another place. In this sense, episodic cognition would enable mental time travel if it enabled experience which introspectively seems to you to be experience of the past or future.

It is widely accepted that the episodic cognition system enables MTT in sense (1), i.e. that it provides representations of the past and future (e.g. Michaelian, 2016b). The mental states you are in as you prospect the future or remember the past can fail to match their target future or past events; so, they have veridicality conditions which involve the future or past and hence are representations of the future or past on most definitions of 'representation' (e.g. Burge, 2010, p. 292). All this still holds even if it is not the function of the episodic cognition system to produce accurate representations (De Brigard, 2014). ${ }^{4}$

Similarly, most will accept that the episodic cognition system enables MTT in sense (2). Recalling the past or imagining the future has phenomenal similarity with the recalled past or imagined future experience..$^{5}$ This is presumably what Tulving means when he says that episodic memory "allows people to consciously

\footnotetext{
${ }^{3}$ If you are a strong representationalist who thinks that representational content determines phenomenology, and the states we are in as we recall the past or prospect the future match (at least some of) the content of the remembered or prospected perceptual states, then (1) entails (2). Similarly, on certain views about the relationship between phenomenology and representational content, (2) entails (1). But these are all substantive views and as a conceptual matter (1) and (2) are independent notions of MTT.

${ }^{4}$ A naïve realist like Debus (2008), or those inclined to something like Noë's (2004) sensorimotor enactivism, may take issue with the claim that past recall and future prospection involve representation. But as has been discussed in the philosophy of perception literature (see Siegel, 2010 ch. 2), there is no reason why a naïve realist cannot in principle accept that these experiences have content. More recently, Sant'Anna and Michaelian (2019, p. 198), adapting an argument from Travis (2004), argue that states of the episodic cognition system leave their contents indeterminate, and hence presumably lack representational content. If correct, this would mean these states are not representations at all.
}

${ }^{5}$ Martin (2001, p. 273) might be an example of someone who denies this claim. Matthen (2010) 
re-experience past experiences" (Tulving, 2002, p. 6). Although the vividness with which people "re-experience" the past (or "pre-experience" the future) varies (Beaty et al., 2019), it is generally accepted that past recall and future prospection involve phenomenal experience. ${ }^{6}$ This experience, although perhaps fainter, matches the target past or future experience to some extent. For example, what it is like for you as you recall eating breakfast is, at least in some respects, what it was like for you to eat breakfast (Debus, 2014; Matthen, 2010). What it is like to imagine the color green being similar but fainter than what it is like to see green (Hume, 1777/1993, p. 10) is a reasonable analogy; the mental image is similar to the percept.

It is fairly trivial that, at least most of the time, the episodic cognition system enables MTT in sense (3). Past recall and future prospection lack phenomenal presence (Martin, 2001, p. 273). We do not normally confuse our recalled episodic memories for perception of the here and now (Tulving, 2002, p. 2) and likewise for our future prospections, although there have been cases of relaxed mindfulness being confused for hallucination in simple experimental conditions of sensory deprivation (Foulkes \& Fleisher, 1975). Past recall and future prospection do not, introspectively, seem to us to be experience of the here and now. We have, as Tulving puts it, "autonoetic consciousness" (Tulving, 1983): we are aware of our recall and prospection experiences as experiences of the past and future (Perrin, 2016, p. 45). While autonoeticity does not entail a lack of phenomenal presence, it would be hard to explain if recall and prospection experiences had phenomenal presence.

\section{MTT as genuine awareness}

The above three notions of MTT are all metaphorical. We shall argue, however, that the episodic cognition system enables MTT in recall but not prospection experiences in the following sense:

4. MTT as genuine awareness of the past: The episodic cognition system enables MTT in the sense that it enables experiences which afford genuine awareness of past events.

Explaining what is meant by 'genuine awareness' will take some work. We need to start with some preliminary ground clearing. As we shall explain, this sense of MTT as genuine awareness of the past, while not literal time travel, goes beyond mere metaphor.

emphasizes the phenomenal differences between recalling an event and the original experience, but this is consistent with much similarity.

${ }^{6}$ This experience is often called 'mental imagery' (e.g. Martin \& Deutscher, 1966; Beaty et al., 2019), although we mostly avoid this term because it is naturally read as presupposing an indirect realist account of recall and prospection experiences. 


\subsection{Direct realism}

There is something it is like to recall an event. As is often said, this episodic recall involves "re-experiencing" the event or "re-living" the original experience. If this recall is MTT in sense (4), then this (re-)experience is an experience of the past event that is being recalled.

Experiencing past events themselves, as opposed to (say) mental images of those events, implies direct realism. Direct realism is the view that we experience the mind-independent world itself, not intermediary mind-dependent objects like mental images or mental representations. In contrast, indirect realism, which involves something akin to mental images, does not allow for MTT in the sense being articulated here.

There are two ways to be a direct realist in the philosophical literature on perception (Crane, 2006). Naïve realism (e.g. Campbell, 2002; Fish, 2009; Martin, 2004), sometimes called relationalism, can be characterized several ways (see Genone, 2016). Put simply it holds that perceptual experiences are relations of awareness to distal sensory stimuli that are unmediated by representations. Representationalism holds that while we experience distal sensory stimuli themselves, that experience is a form of, or grounded in, representations of those stimuli (e.g. Dretske, 1995; Burge, 2010; Speaks, 2015).

Representationalism at first glance seems to not be direct realism. After all, representationalists either take experiences to be, as a matter of metaphysical nature, relations to mental representations (e.g. Sant'Anna, 2020), or simply take them to be mental representations (e.g. Dretske, 2003). But within the philosophical literature on perception, many representationalists take themselves to be direct realists. Dretske (2003, p. 73) says that "seeing a tree [for example] is not to be understood as awareness of some mental intermediary (an image, a sense-datum) having the properties the tree appears to have", but rather as awareness of a tree. Clark agrees:

The kinds of mechanism I have sketched provide a means by which an agent may come to perceive the world. They do not, for example, provide a means by which an agent comes to perceive her own internal representations of the world. For what is perceived are not representations but the world. (Clark, 2012, p. 767)

What is going on? The key is to distinguish between two kinds of directness. Russell (1912/1997), and later Jackson (1977), famously describe the first kind (see also Genone, 2016, pp. 2-3). On this notion of directness, you directly perceives a distal sensory stimulus if and only if you do not perceive it by experiencing something else, like a mental image or sense-datum. The second notion of directness refers to metaphysical nature. Perception is direct if and only if it does not depend on some other state, like the tokening of a mental representation. Representationalism - as understood by philosophers of perception like Dretske (2003), Burge (2010), Clark (2012), and many others - makes perceptual experience direct in the first sense, but not the second. 
Under this version of representationalism, we perceive a distal sensory stimulus when we are in a certain kind of mental state which represents that stimulus. But what we experience while in that state is not the state (i.e., the representation) itself. What we experience is what is represented by that state: the distal sensory stimulus. As Crane (2006, p. 136) explains, the experience itself (i.e., the state of the subject) might be a representation, but what is experienced by the subject in that state is what is represented by it (see also Bernecker, 2008 ch. 5-6). As Dretske (2003) stresses, the distinction between representational vehicles and representational contents is important: the state itself is a representational vehicle, but that vehicle's (wide) content is what is experienced.

Relating this to memory (Michaelian, 2016b, pp. 62-65), while some memory theorists are naïve realists (e.g. Debus, 2008), others are representationalists (e.g. Martin, 2001; Bernecker, 2008). Memory representationalists hold that states of recall are representations (i.e., representational vehicles) of the remembered event, but allow that the (re-)experiences accompanying these states are experiences of the represented past event (i.e., of that vehicle's content). Naïve realists about memory deny that states of recall are representations, saying instead they are metaphysically direct relations of awareness to the past. For both views, during recall, what we experience are recalled events themselves, not representations of them or some other mental intermediary. A representationalist about episodic memory who wanted to emphasize the metaphysical nature of recall experiences might say that their view is a version of indirect realism. Michaelian (2016b, p. 65) uses this terminology, calling memory representationalists like Bernecker (2008) 'moderate indirect realists," ${ }^{, 7}$ although Bernecker rejects this terminology. Given that there are two notions of directness at play, one can use the terminology of 'direct realism' and 'indirect realism' with an eye towards either. We follow the philosophy of perception literature and call all these views 'direct realist', since we emphasize what recall experiences make us aware of.

Nothing stops representationalists from endorsing indirect realism in both senses. Under this view, influentially defended by Jackson (1977) and still found in much of the literature on episodic memory, what we experience when perceiving or remembering are representations. For example, Sant'Anna and Michaelian (2019, p. 197) write "According to representationalism, when we engage in episodic hypothetical thought, the direct objects of our mental states are internal representations of events". Within visual experiences, these representations might be thought of as mental pictures, mental images, or percepts. We will call this version 'indirect representationalism' and use the term 'direct representationalism' for the version of representationalism described above (and endorsed by Dretske, 2003; Bernecker, 2008; Clark, 2012 among others).

\footnotetext{
${ }^{7}$ Elsewhere, Sant'Anna and Michaelian (2019, p. 190) define 'direct realism' to be the view we are here calling naive realism (aka relationalism), i.e. the view that experiences are relations of direct awareness to distal sensory stimuli (like ordinary objects). They also (2019, p. 197) refer to "indirect realism or representationalism", equating the two. Contrast this with Genone (2016, p. 6), who says that to get naïve realism one needs to add further claims to direct realism (e.g., the claim that awareness does not depend on the tokening of a mental representation).
} 
Contemporary philosophers of perception have largely abandoned indirect representationalism because it was initially motivated by the need to explain hallucination and illusion, phenomena which can be handled by direct representationalism. As Genone (2016, p. 6) notes, illusory and hallucinatory experiences can be accounted for "without invoking sense-data or other mediating mental objects. In this respect, representationalism is consistent with direct realism, and can be thought of as one way of developing its central claims." Indirect representationalism is not needed to account for such cases.

Consider the traditional problem of hallucination for direct realism. ${ }^{8}$ The problem supposes that a given successful perceptual experience could, counterfactually, have been a hallucination. Since the experience is the same either way (so the problem assumes), you would be aware of the same thing in both cases. But the counterfactual scenario involves no distal object for you to be aware of, and since the cases are phenomenally indistinguishable, in the actual successful perceptual experience, you are not aware of the seen object itself either. A similar problem arises for direct realism about memory (Sant'Anna \& Michaelian, 2019). False memories or confabulations, like perceptual hallucinations, allow for a parallel track of reasoning against the conclusion that we are aware of remembered events themselves. You could reply that "the direct objects of memory, both in cases of successful remembering and in cases of unsuccessful remembering, are internal representations" (Sant'Anna \& Michaelian, 2019, p. 194). ${ }^{9}$ Indirect representationalists about perception, like Jackson (1977), would have likewise said that the "objects" of perceptual experience (what we experience) are internal representations.

But as noted by Dretske (2003), Bernecker (2008), Genone (2016) and others, direct representationalism is able to handle this problem while saving direct realism. In both the good and bad case (of either perception or memory), what we experience is indeed the same. In both hallucinating and perceiving, according to the direct representationalist, you are in a state which represents some distal object. What you experience is the same, but there is an important difference. What is represented in the good case is an actual perceived or remembered stimulus. In the bad case, there is nothing out in the world which is represented by the (hallucinatory or confabulatory) experience. Imagine you snap a digital photo of your desk. Counterfactually, if you did not have a desk like that, you could have instead made a digital image from scratch which matches the photo pixel-for-pixel. In both cases, what is represented is the same: a certain desk. But in the one case this representation is satisfied; that is, it refers to an actual item out in the world. In

\footnotetext{
${ }^{8}$ This brief discussion is merely intended to be illustrative. For a more exhaustive discussion, with an eye towards memory in particular, see (Bernecker, 2008 ch. 5-6).

${ }^{9}$ This is not the view which Sant'Anna and Michaelian endorse in their paper (2019). Instead, they develop an innovative pragmatist approach to the objects of memory, prospection, and other counterfactual-imaginative experiences. They simply suggest this as the representationalist response to the problem of hallucination and confabulation.
} 
the other case the representation is unsatisfied or remains merely intentional; there is no actual item to which it refers. Experiences, according to the direct representationalist, are the same: sometimes they are satisfied by, or refer to, actual things out in the world, other times not. ${ }^{10}$ A perceptual experience and a matching hallucination can, in one sense, have the same object, while in another sense having different objects. The object of the experience in both cases is what is represented, but only in the good case of perception or memory is that representational content satisfied by something out in the world.

\subsection{Recall as genuine awareness}

The upshot of this preliminary ground clearing is that our thesis should not be rejected out of hand simply because it presupposes direct realism. The claim that we are, in recall experiences, genuinely aware of the recalled events themselves only presupposes direct realism in a weak sense. It only presupposes that we do not experience recalled events in virtue of experiencing some mental intermediary. It does not presuppose whether or not our recall experiences are mediated, or enabled, by intermediary representational states. More importantly, both the naïve realist and the direct representationalist about recall experiences can endorse our thesis. By entailing direct realism, our thesis does not automatically become a version of naïve realism about memory experience (e.g., like Debus, 2008).

Our thesis is also not merely a restatement of direct realism. For the moment, set aside naïve realism (about perception or memory). Consider the difference between veridical perception and perceptual hallucinations, along with the direct

\footnotetext{
${ }^{10}$ We are setting aside a number of important complications, such as the particularity of experience, for simplicity of exposition. According to the dominant account in the literature, prominently developed by Dretske (2003), Burge (2005) and Matthen (2005), experiences are a kind of indexical, or demonstrative, representation. For example, if you see a yellow pencil, you are in a state with the content $X$ is yellow and a pencil, where the open slot $X$ is filled in contextually by the actual object with which you are causally interacting through your visual system. When you successfully perceive a yellow pencil, this slot is filled by the actual pencil you are looking at, and hence the particular token of the visual state you are in comes to represent that particular pencil. When you merely hallucinate a yellow pencil, this slot remains empty, because there is no object with which you are interacting through your visual system. While this does mean that the representational content of the two tokens (the good perceptual token and the bad hallucinatory token) of the visual state differ in their overall representational content, the two tokens still share the (narrow) content fixed by the state type, the content that there is a yellow pencil. Direct representationalists like Dretske, Burge, and Matthen say this is enough to explain the phenomenal similarity between the good the bad cases, as the particular object itself represented by the experience does not affect the phenomenology. Only the general or property-level content that is shared across experience tokens affects phenomeonology. Schellenberg (2011) develops this approach using “gappy” Fregean modes of presentation. Sant'Anna (2020) adapts Schellenberg's approach to the case of memory. There is much debate over whether an account like this can explain all aspects of perceptual experience and the related problems associated with hallucination and illusion. But it is widely thought by direct representationalists that some explanation, along the lines sketched here, provides the tools for saving direct realism from such problems.
} 
representationalist explanation of each just discussed above. If you visually hallucinate a pencil, then a pencil is what you experience while hallucinating. The direct representationalist says that your hallucinatory experience is a representation of a pencil. You experience a pencil because that is what is represented by the experience. But this content of the hallucinatory experience is merely intentional, i.e. unsatisfied. There is no particular pencil out in the world which is represented.

Now contrast what the direct representationalist says about hallucinating a pencil with what they say about seeing a pencil. If you have a successful visual experience of some actual pencil in your environment, your visual experience represents a pencil, just as the hallucination did. But what it represents is an actual object out in the world: the pencil that is stimulating your photoreceptors. Thus, the content of this representation (the content of your perceptual experience) is not merely intentional (Martin, 2001, p. 275). What you experience is an actual object out in the world. As we will say, your visual perceptual experience affords you genuine awareness of this pencil.

So, even if recall experiences are experiences of the recalled events themselves (direct realism), there is still an open question of whether they are more like the case of perception or the case of perceptual hallucination. As you episodically recall some past-perceived event, is what you experience a mere intentional content, or do you instead actually experience the event? When we say that recall experiences afford genuine awareness of recalled events, we mean that they are experiences in the latter sense. Our talk of 'genuine awareness' is meant to capture that recall experiences do not merely make subjects aware of recalled events as mere intentional contents.

It may seem that this distinction applies to perception but not to recall experiences. At first glance, what seems to make the content of a perceptual hallucination merely intentional is that there is no distal sensory stimulus out in the world to be experienced. In contrast, what is recalled in successful recall experiences are actual past-perceived events. Hence, if the recall experience is successful and represents some actual past-perceived event, would not the content of that experience necessarily be satisfied, and so not "merely intentional"? This move is too fast. Consider how you can hallucinate real objects. For example, you can visually hallucinate your favorite pencil when it is nowhere near you to be seen. In this case, what you experience (your favorite pencil) is a merely intentional content, even though that content represents an actual thing out in the world (assuming you have a favorite pencil).

What makes the difference between genuine awareness and experiencing a mere intentional content is a certain kind of contact between subject and thing experienced. A hallucination of your favorite pencil is an experience of a mere intentional content, and not that pencil itself, because the experience fails to actually put you in contact with it. Genuine awareness of a distal sensory stimulus happens when perceptual experience "brings" that stimulus "into consciousness." 11

\footnotetext{
${ }^{11}$ Debus (2014 footnote 12) draws a similar distinction. What we have called 'genuine awareness'
} 
Keep in mind that this notion of genuine awareness is perfectly compatible with direct representationalism. Indeed, direct representationalists about perceptual experience see themselves precisely as giving an account of how the senses manage to bring into mind distal stimuli. For example, here is Clark again discussing his predictive-processing representationalist view of perceptual experience: ${ }^{12}$

Considered in this way, the mechanistic story on offer simply shows how beings like us are able to achieve genuine access to the causal structure of our environment. They show, as my colleague Matt Nudds once put it to me, how it is that we can be "open to the world". [...] Equipped with brains like ours we become porous to the world. (Clark, 2012, p. 767)

For the direct representationalist, we bring distal stimuli "into mind", or "into consciousness", by representing them in the right way. A hallucinatory experience of (or rather: "as of") your favorite pencil, although representing it, does not put you in the sort of representational contact necessary for genuine awareness.

The question then becomes whether recall experiences (at least the successful ones not based on false memories) afford genuine awareness, or whether instead (like perceptual hallucinations) they involve experience of mere intentional contents. We argue in the next section that recall experiences (when successful) afford genuine awareness.

So far, we have focused on direct representationalist accounts. As noted above, Debus (2008) argues for a naïve realist (or as she calls it, relationalist) account of memory in which recall experiences are direct relations to the recalled event. Recall, in this view, involves not only (as we are calling it) genuine awareness of some past event, but also that awareness itself has the metaphysical structure of a relation. Episodically remembering a past event is just a way to be related to it. Our thesis, that recall experiences involve genuine awareness, is entailed by, but is weaker than, this view. We are not arguing for naïve realism (i.e., relationalism) and having genuine awareness of past objects through memory does not require it. While we agree with Debus that memory (when successful) allows us genuine awareness of past events, we leave open the metaphysical nature of this awareness. In our view, recall experiences could be representational states in which (following the direct representationalist account outlined just above) the subject experiences what is represented. The arguments we give in the next section for our claim are also different from those given by Debus. Debus (2008) gives (a) a positive argument which parallels Campbell's (2002) claim that naïve realism is necessary to see how perception (or, in Debus' case, memory) affords understand-

is what Debus describes as factive experiential awareness, while what we have called 'experience of a mere intentional content' is what Debus describes as experience "as of" an object.

${ }^{12}$ The naïve realist might object that, because of the similarities (on the direct representationalist account) between perception and the hallucination, the perceptual experiences do not really (on the direct representationalist account) put one in contact with distal stimuli (e.g., see Fish, 2009, p. 14). We are not here to adjudicate this dispute. 
ing and knowledge of demonstrative claims, and (b) various replies to the typical objections made to naïve realism. Our arguments, for the weaker claim that recall experience involves genuine awareness, will instead focus on the causal structure of memory.

If we are right that successful recall experiences involve genuine awareness of past-perceived events, why does this amount to MTT in a way that goes beyond mere metaphor? The main idea is that genuine awareness of a past-perceived event would entail that that past event is "brought into consciousness" (as we might put it), or (alternatively put) that our state of recall extends back into the past to include that event. To borrow some evocative language from the naïve realists, when you make experiential contact with the world, the world itself "shape[s] the contours" of your experience (Martin, 2004, p. 64); there is "an incursion or intrusion of the objective within the nonobjective - of 'brute' nonconscious matter within conscious life" (Hellie, 2014, p. 247). As Debus (2008, p. 418) says, your "point of view extends over" the part of the world of which you are conscious. This metaphorical talk of "bringing" a past event "into consciousness", or a mental state "extending" over the past event can be cashed out in terms of constitution. It is often assumed within philosophy of mind that experiences are constituted (at least in part) by the things of which they make us aware. ${ }^{13}$ Specifically: what it is like for you to have an experience just is (at least in part) what the experienced thing is like. For example, if you were asked what it is like to visually experience a pencil, all you could really do is describe the pencil you see. So, what an experience makes you aware of becomes a constitutive part of the experience.

This term 'constitutive part' raises some subtle issues. As noted by Fish (2009, pp. 10-11), the idea that what we experience is a constitutive part of our experiences has been endorsed by both direct representationalists like Dretske (2003), Tye (1995), and Lycan (2001), as well as by naïve realists like Fish himself (2009) and Martin (2004). When naïve realists (including Debus) make this claim, they are claiming that the experience is a state of a type which necessarily involves the object or event experienced. When direct representationalists make the claim, they of course need to allow that any given experience is of a type which can be instanced even without the object or event that is being represented. ${ }^{14}$ Hence the constitution claim, on their view, should be taken as a claim about experience tokens, not types. Say you successfully perceive, or successfully remember perceiving, some distal object or event. While the distal object or event is not necessary for having another experience of the same type, and hence is not a constituent part of the experience type, it is a constituent part of the particular token instance of that type which you enjoy as you perceive it.

\footnotetext{
${ }^{13}$ When you add in the qualifier 'at least in part' (as we have done here), the claim should be amenable even to qualia theorists who think there are some properties of experience not identifiable with properties of what is experienced.

${ }^{14}$ In contrast, since naïve realists are mostly all disjunctivists, the issue of hallucination doesn't arise from them. They say that when I have an experience of an object, that experience type includes that particular object as a constituent part. Since the experience is of a type that constitutively involves the object perceived, that experience type can't be reproduced in a hallucination.
} 
To summarize: if recall experiences afford genuine awareness of past events instead of simply presenting those past events as mere intentional contents, then they put us in contact with the past itself. The recalled event itself literally shows up within our experience, as a constituent part. While this does not amount to literal travel through time, it certainly makes talk of MTT more than mere metaphor. ${ }^{15}$

\section{Does episodic cognition enable genuine awareness of the past?}

We noted above that direct realism about recall experiences actually leaves open two possibilities: successful recall experiences could afford genuine awareness of what is recalled, or instead their contents could be merely intentional. The aim of this section is to argue for the first possibility, assuming direct realism. If a naïve realist account of memory like Debus' is true, then successful recall experiences (i.e., ones which involve recalling actual past-perceived events) will necessarily involve genuine awareness of the recalled events. Experiences with merely intentional content are only possible for direct representationalists because, for them, awareness is mediated by representations. It is possible to represent something that is not really there, or with which you are not really in contact, and so it is possible to have an experience that does not put you into contact with anything. Since the naïve realist denies that awareness is mediated by representations, you are aware of something only if there exists some actual distal object or event of which you are aware. So, if a naïve realist account of (successful) recall experiences is correct, it follows immediately that episodic cognition enables genuine awareness of the past. Hence, any arguments for a naïve realist account are arguments for the claim that episodic cognition enables genuine awareness of the past.

Debus (2008) is one of the few theorists who have defended a naïve realist account of recall experiences. ${ }^{16}$ She also argues (2014) that a similar account will not work for the experiences involved in future prospection. Her reasoning is straightforward: since future events are not yet actual, it is not possible to be genuinely aware of them. A similar, parallel worry can be raised for naïve realism about episodic memory: you might think past events no longer exist, and if not, you could not be conscious of them in a recall experience (Michaelian, 2016b; Moran, 2019; Sant'Anna \& Michaelian, 2019). Note that the same problem will arise for the proposal that recall experiences involve genuine awareness of the past, even if

\footnotetext{
${ }^{15}$ We want to thank a reviewer for pressing us to clarify our claim that recall experiences involve MTT in some non-metaphorical sense. As they helpfully summarized our view, "the subject just 'reaches out' to the past mentally, from the here and now in which she remains mentally anchored".

${ }^{16}$ Debus, in her (2014) account, does not notice that her account entails a sense in which episodic memory is more than mere metaphor. She takes the MTT talk to be purely metaphorical.
} 
it is developed within the direct representationalist framework. If past events do not exist, then we cannot be genuinely aware of them, as that awareness entails their constitutive involvement in the (at least token) experience.

We want to set aside both naïve realism and this metaphysical problem. Since naïve realism is highly controversial (and not necessary for our thesis), it is more interesting to ask whether arguments for our thesis can be given independently of arguments for naïve realism. The metaphysical problem rests on deep questions about whether past objects and events really exist, questions which are outside the scope of this paper. ${ }^{17}$ While a final, definitive analysis of the issue will, of course, require some discussion of these metaphysical issues, we are instead more interested in pressing the discussion from the standpoint of empirical psychology and neuroscience. The interesting question, as we see it, is whether there is a case to be made, on the basis of the psychological facts, for or against the claim that recall experiences involve genuine awareness of the past.

At first blush, there is a case to be made for the claim that recall experiences involve genuine awareness of the past. To start, consider the cases of perception and perceptual hallucination and what makes perception (but not hallucination) a case of genuine awareness. Roughly, perception and hallucination are distinguished by the involvement of causal-informational links in the former. The reason a hallucinatory experience of your favorite pencil is merely "as of" that pencil and fails to make you genuinely aware of it is that your sensory systems are not interacting with it. There is no concurrent causal connection or information-carrying link between the pencil and your (hallucinatory) experience as there is when you perceive it. In perception your sensory systems interact with your favorite pencil in a way that couples your experience to it (Chisholm, 1957, p. 149): what it is like for you as you perceive it depends on what it is like at present, as you interact with it through your sensory systems.

Now, it is plausible that this sensory interaction is what distinguishes perceptual experiences with mere intentional content (i.e., hallucinations) from successful perceptual experiences that afford genuine awareness of the distal world. If a perceptual experience of an object is generated via sensory interaction with that object so that the experience is coupled to the object, then it yields genuine awareness. ${ }^{18}$ The recall experiences of episodic memory are not perceptual experiences, but they still satisfy this condition. They are (at least when successful) generated by an information-carrying sensory interaction with the recalled event via memory traces. For example, what it is like for you as you recall eating breakfast this morning depends on what that event was in fact like as you interacted with the meal through your sensory systems.

\footnotetext{
${ }^{17}$ Michaelian (2016b, p. 63), Sant'Anna and Michaelian (2019, p. 191), and Moran (2019) say that the view that past or future objects really exist (eternalism) is highly unintuitive, but at least one author of this paper disagrees.

${ }^{18}$ The qualifier that the experience is of the object is important. We are not suggesting that a causal link or coupling is sufficient for an experience to be of an object, only that if an experience is of an object and is causally coupled to that object, then it affords genuine awareness.
} 
The causal theory of memory accepts as a basic premise that episodic memory involves this causal-informational link to the recalled events (e.g. Martin \& Deutscher, 1966; Bernecker, 2008). It also is supported by the neurobiology of memory (Debus, 2008, p. 411). During an initial sensory interaction, reciprocating patterns of neural activity cycle through sensory cortex and other related neural circuits. These patterns of activity tune synaptic connections between neurons via synaptic plasticity. This tuning primes the circuit to repeat the patterns when and if they are later partially reformed by other neural input, whether that input is stimulus-driven or top-down from extraperceptual processing (Feldman, 2012; Jackson, 2013; Zylberberg \& Strowbridge, 2017). This priming facilitates episodic memory: episodic memories are recalled when partial inputs prompt the completion of activity patterns from previous sensory interactions (Brogaard \& Gatzia, 2017, p. 9). The distributed effect of the synaptic tuning from the original pattern (which primes the circuit to repeat it) is the memory trace which is so often discussed in theorizing about memory (Liu, Ramirez, Redondo, \& Tonegawa, 2014, p. 59).

We can summarize the argument for genuine awareness of the past in episodic memory as follows:

P1. Recall experiences of the past depend on the neural patterns reactivated in the recall.

P2. These neural activity patterns depend on the synaptic tuning which primed the neural circuit to repeat them.

P3. This synaptic tuning depends on the original pattern of activity which shaped it.

P4. That original pattern of activity was due to a particular past sensory interaction with particular objects in a particular event.

Conclusion 1: Recall experiences of the past depend on these particular objects and events and what those objects and events were like.

P5. If a recall experience of the past is of a past-perceived event and causally depends on that event and what it was like, then that experience involves genuine awareness of the event itself. ${ }^{19}$

\footnotetext{
${ }^{19}$ It might be objected that just because what it is like to recall the past depends on a particular event does not mean that what it is like to recall the past just is what that event was like. This is correct. But P5 is not meant as a conceptual truth. P5 is motivated by noticing that it is the dependence of perceptual experiences on the perceived object itself, via a causal-informational link, which seems to make the difference between them and hallucination. So long as the dependence of a recall experience on its past target is sufficiently like the dependence of a perceptual experience on its target, we can infer that both recall experiences and perceptual experiences involve the same kind of awareness: genuine awareness. Note that this is not a move from causal dependence to the claim that experience is a simple, nonrepresentational relation to its object. Rather, the premise
} 
P6. Recall experiences of the past are of past-perceived events.

Conclusion 2: The recall experiences of the past that occur in episodic memory involve genuine awareness of the remembered events themselves.

Note that this argument runs independently of whether we assume direct representationalism or naïve realism. P1-4 capture the neurobiological facts underlying past recall, while P5 gives a sufficient condition for genuine awareness which both direct representationalists and naïve realists can accept. P6 is just direct realism about recall experiences.

It is important to reiterate that P1-4 assume successful recall. Many times, when we recall episodic memories, the resulting recall, or perhaps the whole memory trace itself, is distorted to the point of fabrication. Similar to how we can hallucinate and seem to perceive what is not there, we can misremember and seem to remember what did not happen. In that case, it is clear that our defective recall experience of the past does not depend on the particular items being remembered. In these cases, the recall experience's content is merely intentional and does not afford genuine awareness of any past event. ${ }^{20}$ Presumably, in these cases the causalinformation link discussed in P1-4 will itself be defective. So nothing about this argument, or our position, entails that episodic recall is always accurate or always affords genuine awareness of the past. Just as perceptual experiences, such as hallucinations, can fail to afford genuine awareness of distal sensory stimuli, episodic recall will likewise fail to afford genuine awareness of recalled events when things go wrong.

As we noted above, we are restricting our claim to recall experiences, not all experiences generated by the episodic cognition system. This is because you cannot run a similar argument for future prospection. There is no analogous causalinformational link to the future (Sant'Anna \& Michaelian, 2019, p. 193). Presumably, prospection experiences have only merely intentional content. They do not afford us genuine awareness of the future, i.e. they do not put us into experiential contact with the future. So, if this argument is successful, then there is an asymmetry between past recall and future prospection: one puts us in experiential contact with times outside the present while the other does not. Debus (2014) notices this potential asymmetry, although she takes the further step of inferring that because past recall but not future prospection involves experiential contact with events outside the present, the two are different kinds of mental states. Similarly, Perrin (2016, pp. 50-51) lands on a direct representationalist account of recall experiences

moves from the causal dependence of the memory on the remembered event and the memory being an experience of that event to the memory being a certain kind of experience: the kind that affords genuine awareness of its object. Memory as genuine awareness of the past does not entail naïve realism (relationalism).

${ }^{20}$ At least, this is what a direct representationalist about memory would say. The naïve realist will have to give a disjunctive account which treats these unsuccessful cases of memory as fundamentally different from the successful cases. 
as involving (as we are calling it) genuine awareness of the past while prospection experiences involve awareness of the future only in the sense of having future events as mere intentional contents. ${ }^{21}$ From this asymmetry (as well as others), he argues that past recall and future prospection are facilitated by different cognitive processes. We do not think this inference follows. The above argument is not intended to support any claims about past recall and future prospection being different kinds of states or being facilitated by different kinds of cognitive processes. Consider successful perception and hallucination. According to direct representationalism, the former involves genuine awareness while the latter only involves experiences with merely intentional contents. But according to direct representationalism, the two are not different kinds of states nor supported by different systems. Since our argument and conclusion are consistent with direct representationalism about recall experiences, disjunctivism is not implied.

It is worth noting that even normal perception involves some MTT, i.e. some genuine awareness of objects outside the present. Both perception and memory are delayed in terms of the occurrence of the relevant event and the experience of that event. We never perceive, visually or otherwise, events contemporaneously as they happen, since processing takes time. ${ }^{22}$ Perceptual experiences present the past - how far into the past depends on how spatially distal the object is from the perceiver and how long it takes to process the information received via the senses. The light from stars can take billions of years to reach us, and we perceive milliseconds into the past when we look at objects nearby. Temporal delay is not simply an incidental feature of perception but also necessary for some attributes of our experience. For example, the short delay between a sound being received by the two ears when they are not equidistant from the source partly accounts for our ability to detect the direction from which the sound emanated (Mather, 2016). If temporal delay is a constant and necessary feature of perception, the temporal delay of memory itself is not a distinguishing feature, although the cause of the delay is distinct, i.e. storing and retrieving for memory vs. the travel and processing of stimulus for perception. ${ }^{23}$

We have argued that there is a plausible case to be made for memory as genuine awareness of past events. However, issues for this view arise under particular theories of memory, especially those that take memory to involve reconstruction. Despite this, we argue that there is still room for our thesis under these views.

\footnotetext{
${ }^{21}$ Like Perrin, Martin (2001) lands on a direct representationalist account of recall experiences as involving genuine awareness of the past, although he does not give an argument like the one developed here. So, Debus (2008), Martin (2001), and Perrin (2016) endorse accounts on which episodic recall experiences afford genuine awareness of the past.

${ }^{22}$ Predictive processing adds further complexity to this account. We discuss this alternative in section 6 .

${ }^{23}$ It is possible that neither memory nor perception should be viewed in the way proposed. However, this goes beyond the goals of this paper. We simply mean to argue that successful memory can be considered as affording genuine awareness to the extent that successful perception can.
} 


\section{Constructivist views of episodic memory}

Modern theories claiming that memory is a reconstruction rather than a replaying of past events pose a prima facie challenge to our interpretation of episodic memory. According to some theorists, memory does not even require a causal link to past events. If correct, would past recall still count as genuine awareness of past events? We argue that even these theories of memory which appear most contradictory to our view are in fact consistent with it.

What exactly is episodic memory? It can be contrasted with what is known as 'procedural memory' in psychology (Anderson, 1976; Tulving, 1983; Winograd, 1972) or 'know how' in philosophy (Ryle, 1945), which involves skills or abilities. Memory for facts is known as 'propositional' or 'semantic memory' (Quillian, 1968; Tulving, 1972). Procedural and semantic memory are, for a good reason, sidelined in this discussion since they do not give the rememberer access to the past qua their own experienced past, and are ahistorical. The context in which these memories were experienced is not maintained as part of the memory. If this context is carried over, then there is a separate, episodic memory. For example, remembering where you were when you learned about the toxicity of vitamin A in a polar bear liver involves both episodic and semantic memories. For this reason, we are concerned with recollective, episodic or autobiographical memory, which involves remembering personal events from a first person perspective (Brewer, 1986).

Historically, normally working episodic memory has been described as giving us access to the past through the preservation of sense impressions (Hume, 1739/2000) or internal representations that are later reactivated (Martin \& Deutscher, 1966). However, the view that memory simply replays past experiences has been largely rejected. Memory is not simply stored information which is then later retrieved (Martin, 2001). Rather, according to constructivists, memory involves constructing "plausible representations of past events" (Robins, 2019, p. 2136) instead of simply replaying stored representations of those events (see Michaelian, 2011; De Brigard, 2014). This constructive nature is evinced by how memory often involves the entwining of multiple events and is "blended, not laid down independently once and for all, and [...] reconstructed rather than reproduced" (Sutton, 1998, p. 2). Memory rebuilds past representations on each recall (Michaelian, 2016a). Forgotten sections are filled in with memories of separate events or confabulated, for example, by inference making or imagination.

De Brigard (2014) likewise argues that memory is a process in which mental representations are optimised under probabilistic constraints. This brings together both encoded data of previous experiences and, with the same optimisation algorithms, fills the gaps where previous experience has not been encoded with information about what probably happened. Sometimes, this information is an optimal construction, but when there is deviation from optimality, this is what we consider to be a misrepresentation or false memory. Sutton (2003) notes that despite this turn from defining memories as accurate representation, this reconstruction 
process does not necessarily render memories false, and at the same time, it does not entail that no memories can be classified as false. Rather, all memories, both veridical and false, are constructed, and assessing memories as the former or the latter requires greater nuance. Constructivists point out that reconstruction is necessary because we never remember an event in its entirety, and yet our memory is not usually experienced as being gappy.

One clear example of how memory can be both veridical and at the same time reconstructed differently from the initial experience is when the perspective switches, so that the event is viewed from a different angle (Rice \& Rubin, 2009). This observer perspective is commonly from a bird's eye view. The original field perspective is not represented accurately, which can be immediately determined since that particular angle of perception would be physically impossible, but the events portrayed in the memory are often sufficiently accurate to be considered a true memory. Although this is only one example, under this view, reinterpretation is the norm, not the exception.

Some theorists even deny that the purpose of memory is to give us knowledge of past events. Another alternative is that memory is about life coherence. It enables us to "produce a coherent life history" (Schechtman, 1994, p. 13). In this view, memory is a narrative that provides the important purpose of informing us of who we are as individuals. This not only incidentally but necessarily involves biases and reconstructions.

While the aforementioned views describe remembering as involving reinterpretation of encoded data or stored memory traces, which can be more or less accurate, others reject the view that such traces are a necessary element of veridical memory altogether. Michaelian (2016a, 2016b) rejects "causalist" theories according to which a causal connection with the event remembered is essential for an experience to be classified as successful remembering. Instead, three conditions need to be met: accuracy, reliability and internality. Internality is what distinguishes remembering from relearning, in which information that has been forgotten is relearned from an external source. This is not to say that causal factors, retention and access of information are never the cause of any token memory, but rather they are not the criterion. Michaelian (2016a, p. 10) says "simulationism is compatible with the view that remembering often does involve retention: the simulationist's claim is that remembering does not necessarily involve retention, not that it necessarily does not involve retention". We could, for example, have a genuine accurate memory that is generated by some other process, such as inference making, that lacks any direct causal memory trace. So long as the process is reliable, comes to an accurate interpretation of events and is internal, it is memory irrespective of the process of memory generation.

Here, we do not aim to espouse the various strengths and weaknesses of these competing views, but rather analyse whether our thesis is consistent with them. Anti-causalist views will be the most challenging, however, we believe it can be done. 


\section{The constructivist challenge to a genuine awareness account of memory}

Constructivist and anti-causalist views threaten to undercut our central premise that there is causal or informational dependence between a recall experience and the remembered event (Sant'Anna \& Michaelian, 2019, pp. 195-196). The constructivist would suggest that any given memory depends on a blending of cognitive features rather than simply such informational dependence. In the more extreme case of the anti-causalist, the dependence on neural patterns that occurred during the original experience is removed altogether, rejecting P3 of our argument, the premise that synaptic tuning of the relevant memory depends on the original pattern of activity which shaped it. If recall experiences are blended, or worse, if they need not have causally originated at all in the remembered event, can they afford genuine awareness of the past?

First, let us start with the more radical anti-causalist position. Anti-causalists like Michaelian do not claim that no recall experiences are grounded in a causalinformational link to the recalled event. Their claim is just that such a link is not necessary for successful recall. Hence, a conciliatory approach is available. In line with our argument from section 4, we allow that the content of causally-detached recall experiences, when they occur, is merely intentional, but still hold that successful recall experiences which do have a causal-informational link afford genuine awareness.

One might worry that this conciliatory approach is unstable. ${ }^{24}$ If only some successful recall experiences involve genuine awareness of the past and others do not, what difference does genuine awareness make? Would it not be a simpler theory to deny that any of the cases involve genuine awareness of the past? Our response to this worry is that simple theories are only to be preferred when there is no evidence providing greater support for the more complicated theory. We argue that when taking into account the empirical evidence, it is not plausible to simply claim that genuine awareness plays no role whatsoever. In line with our main argument from section 4, even if anti-causalism is true, some recall experiences still do have causal-informational links to the recalled event and are still dependent on the remembered event, and this dependence makes a difference for token memories. Specifically, this dependence puts us into contact with the recalled event, or "brings it into consciousness".

What about memories which retain some causal link to what is remembered, but still involve distortion and reconstruction? We agree with Martin (2001, p. 282), who notes that "direct contact with the past is still consistent with the idea that there is much fabrication in recall". In support of this view, we highlight the analogy between memory to perception. Since normal, successful perception can itself be constructed or have a tenuous causal connection to the distal stimulus

${ }^{24}$ Thank you to a reviewer for this and the following suggestions. 
but still afford genuine awareness, these features of memory should not be seen to disqualify it as affording genuine awareness. Let us consider this comparison with perception in more detail.

According to Bayesian brain approaches, perception of the world arises from unconscious inference making (Helmholtz, 1924/2005). This view rejects the assumption that perceptual content is extracted from sensory stimulation. Rather, the content of our perceptual experience involves "hypotheses" about events and objects in the world (Gregory, 1980). Perception is a process of inference making based on priors $^{25}$ under the Bayesian framework, and these priors become more relied upon when there is more ambiguity in the environment, say, in poor lighting (Kersten \& Yuille, 2003). An influential solution to how Bayesian principles can be applied to experience is the predictive processing framework of perception, according to which perceptual content is a prediction of sensory input that is updated when it comes into conflict with that input. A key element of perception, on this view, is prediction error minimisation (Friston, 2003; Friston \& Stephan, 2007; Rao \& Ballard, 1999) or free energy minimisation (Friston, 2010), which involves the attempt to minimise the error between predictions about what should be perceived and sensory inputs (Clark, 2013). Crucially, some theorists believe this is all there is to perception (e.g. Hohwy, 2013, 2016). Metzinger (2009) similarly considers the content of perception to be a transparent unified world model of the present time. Perception, on this view, involves a complex interweaving of "shortterm memory and working memory, with recurrent loops in neural networks, and with the binding of single events into larger temporal gestalts (often simply called the psychological moment)" (Metzinger, 2009, p. 35).

According to these views, perceptual experience is distorted and constructed in much the same way as constructivist views of episodic memory. Memory and perception are both constructed in order to give us an informational link to the environment, and these can be assessed for accuracy. If this constructive aspect of perception does not preclude perception from affording genuine awareness (Drayson, 2018), the same applies for episodic memory.

Predictive processing views of perception also invite a second look at anticausalist views of episodic memory. On closer analysis, the anti-causalist view of episodic memory is not so distinct from the interpretation of predictive processing according to which perceptual content is just prediction constrained by sensations (Friston \& Stephan, 2007). This interpretation makes even successful perception itself a kind of "controlled hallucination" (Clark, 2015, p. 14). By describing sensory input as a constraint to rather than a cause of perception, Michaelian's anticausalist description of memory is quite analogous. But if this merely constraintbased nature of perception does not preclude it from affording us genuine awareness of the environment, neither should it preclude successful recall from affording genuine awareness of the past. We can still retain the kind of connection with the real world required for genuine awareness via constraints imposed by the environ-

\footnotetext{
${ }^{25}$ The probability distribution based on previous input.
} 
ment. So long as the relevant experience, whether perceptual or recall, depends on or is linked to the object or event, it provides genuine awareness of that object or event, even if there is no causal link.

This analogy between the anti-causalist view of memory and perception as "controlled hallucination" may not seem entirely apt. Even if sensory input is merely a constraint on the perceptual predictions affording the content of our perceptual experiences, sensory input still provides a sort of causal connection to the world that the anti-causalist claims can be missing from memory. For example, the anti-causalist might have in mind the following sort of case. Say the original memory trace laid down during your perception of an event is lost via forgetting, but later you see video that you took of the event. Watching the video lays down new memory traces that are accurate of your original experience, and subsequent recall experiences of the event are reconstructed by activating these new memory traces.

In reply, we want to suggest that there might be instances of perception which are analogous to even the most extreme causal-disconnection in the memory. As aforementioned, higher ambiguity in sensory input means priors become more relied upon than that sensory input. Does perception still afford genuine awareness of a distal stimulus when it relies heavily, or even entirely, on priors? More often than not, we do a good job at correctly inferring, based on priors, the distal causes of our sensory input. We might still take a perceptual experience to involve genuine awareness of its object if, say, the priors did a good job of representing the world accurately through correct inference making in absence of the relevant stimulus.

A good example of prediction outweighing sensory input in the case of ambiguity is the mask illusion, and relatedly, perception of faces. A widely accepted explanation as to why it is nearly impossible for neurotypical individuals ${ }^{26}$ to see the inside of a mask as hollow is because of our priors about seeing faces. Whether it is convex or concave is underdetermined by the visual cues, but faces are almost never experienced as hollow. Because of their salience and importance for processing, both concave and convex masks are interpreted as being convex (Dima et al., 2009; Gregory, 1980). It is well accepted that what we see is determined by both retinal and several extra-retinal factors, with memory, arguably, being the main contributing extra-retinal factor (Albright, 2012). One could say that the perceived convexity of a mask or even a face is priors-driven rather than stimulus-driven since the distinction between convex and concave is ambiguous. One can then infer that perception of convex masks or normal faces is accurate perception in the absence of disambiguating stimuli. These perceptions are reliable, in Michaelian's criteria, simply because faces and masks are usually convex.

However, one might argue that despite elements of perception being entirely priors driven, perception of, say, an entire visual scene or event must involve some direct causal link in order to be both veridical and reliable. Even ambiguous sensory inputs provide some direct causal constraint. In contrast, memory of an entire

\footnotetext{
${ }^{26}$ Some individuals with schizophrenia do not see the illusion.
} 
event might be reliable in some other way - for example, being told about something you did as a child and "remembering" it accurately based on this telling of the event plus some good imaginative work and inference making. However, the view that a causal link is not part of the criterion of memory does not exclude the possibility that this link is, in practice, necessary for most reliably accurate memories. Martin (2001, p. 282) notes that the important sense of memory as genuine awareness would be "lost if episodic memory had no special status in an account of our epistemic links with the past". Nonetheless, if it turns out that causal connectedness, or at least some informational link, is not a requirement of all reliable, accurate episodic memories, we can fall back on the conciliatory approach outlined at the start of this section. We argue that there is a case for saying that even causally-disconnected successful memories afford genuine awareness of the past, but if this argument fails, the causally-connected ones at least still afford genuine awareness.

\section{The function challenge}

Part of our response above was to claim that accurate tracking of the environment may suffice for the kind of contact which makes the difference between the genuine awareness of perception and the mere intentional content of hallucination, even if this tracking is not achieved by robust causal links. Another challenge to our view of memory is that the function of memory is not even to represent the past accurately. Memory is a key aspect of the sense of self in theories of psychological continuity of personal identity (Parfit, 1971) and is important for our life narrative or trajectory (Schechtman, 2011). Because of this, there are a variety of biases that affect what and how we remember events. This is particularly obvious regarding emotional salience, which can alter both the likelihood that an event will be remembered and the associations related to these memories (Kensinger, 2009). We can then ask whether perception carries similar functions. It does seem that salient factors can alter perception in a variety of ways. Reward and punishment, for example, can affect what is perceived in binocular rivalry experiments in which two different visual stimuli are presented to different eyes and perception shifts back and forth between the two. Balcetis, Dunning, \& Granot (2012) found that after teaching participants to associate values to specific letters and numbers, specifically a monetary prize as the reward for earning points, the stimulus with a higher point value becomes dominant, i.e. participants are more likely to see that stimulus first and for longer. This is just one way in which value biases perception similarly to how biases affect memory.

There are many biases and potential functions to memory as there are to perception, but we see this as no reason to reject the view that most memories involve contact with recalled events. If under these views, there are some mental states that do not accurately represent past events but should still be classed as memories, then we again adopt the conciliatory approach; these token memories are not cases of genuine awareness of the past. 


\section{Conclusion}

We have argued that episodic memory enables genuine awareness of the past. Memories are (at least sometimes) reactivated neural patterns that depend on and repeat an original pattern of activity that occurred during the initial experience of an item or event. Because of this, episodic recall experience involves genuine awareness of the event that was originally experienced. We have argued that this view is still applicable under theories of memory that appear, at first glance, to be incompatible with it, namely constructivist and anti-causalist views. However, particular token memories under such views may involve no causal link with the past and thus may not afford genuine awareness of past events.

\section{Acknowledgments}

We would like to thank the anonymous referees and editors of this journal for their helpful comments which much improved our paper. Rosen received funding from Carlsbergfondet (CF16-0804).

\section{References}

Albright, T. D. (2012). On the perception of probable things: Neural substrates of associative memory, imagery, and perception. Neuron, 74, 227-245. https://doi.org/10.1016/j.neuron.2012.04.001

Anderson, J. R. (1976). Language, memory, and thought. Hillsdale: Lawrence Erlbaum Associates.

Balcetis, E., Dunning, D., \& Granot, Y. (2012). Subjective value determines initial dominance in binocular rivalry. Journal of Experimental Social Psychology, 48(1), 122-129. https://doi.org/10.1016/j.jesp.2011.08.009

Beaty, R. E., Seli, P., \& Schacter, D. L. (2019). Thinking about the past and future in daily life: An experience sampling study of individual differences in mental time travel. Psychological Research, 83(4), 805-816. https://doi.org/10.1007/s00426-018-1075-7

Bernecker, S. (2008). The metaphysics of memory. New York: Springer.

Brewer, W. F. (1986). What is autobiographical memory? In D. C. Rubin (Ed.), Autobiographical memory (pp. 25-49). Cambridge: Cambridge University Press.

Brogaard, B., \& Gatzia, D. E. (2017). Unconscious imagination and the mental imagery debate. Frontiers in Psychology, 8(799), 1-14. https://doi.org/10.3389/fpsyg.2017.00799

Buckner, R. L., \& Carroll, D. C. (2007). Self-projection and the brain. Trends in Cognitive Sciences, 11(2), 49-57. https://doi.org/10.1016/j.tics.2006.11.004

Burge, T. (2005). Disjunctivism and perceptual psychology. Philosophical Topics, 33(1), 1-78. https://doi.org/10.5840/philtopics20053311

Burge, T. (2010). Origins of objectivity. Oxford: Oxford University Press.

Byrne, A. (2010). Recollection, perception, imagination. Philosophical Studies, 148, 15-26. https://doi.org/10.1007/s11098-010-9508-1

Campbell, J. (2002). Reference and consciousness. Oxford: Oxford University Press

Chisholm, R. (1957). Perceiving: A philosophical study. Ithaca: Cornell University Press.

Clark, A. (2012). Dreaming the whole cat: Generative models, predictive processing, and the enactivist conception of perceptual experience. Mind, 121(483), 753-771. https://doi.org/10.1093/mind/fzs106

Clark, A. (2013). Whatever next? Predictive brains, situated agents, and the future of cognitive science. Behavioral and Brain Sciences, 36(3), 181-253. https://doi.org/10.1017/S0140525X12000477

Clark, A. (2015). Surfing uncertainty: Prediction, action, and the embodied mind. Oxford: Oxford University Press.

Crane, T. (2006). Is there a perceptual relation? In T. Szabo Gendler \& J. Hawthorne (Eds.), Perceptual experience (pp. 126-146). Oxford: Oxford University Press.

Barkasi, M., \& Rosen, M. G. (2020). Is mental time travel real time travel? Philosophy and the Mind Sciences, 1(1), 1. https://doi.org/10.33735/phimisci.2020.1.28

(c) () ( T) The author(s). https://philosophymindscience.org ISSN: 2699-0369 
De Brigard, F. (2014). Is memory for remembering? Recollection as a form of episodic hypothetical thinking. Synthese, 191, 155-185. https://doi.org/10.1007/s11229-013-0247-7

Debus, D. (2008). Experiencing the past: A relational account of recollective memory. Dialectica, 62(4), 405-432. https://doi.org/10.1111/j.1746-8361.2008.01165.x

Debus, D. (2014). "Mental time travel": Remembering the past, imagining the future, and the particularity of events. Review of Philosophy and Psychology, 5, 333-350. https://doi.org/10.1007/s13164-014-0182-7

Dima, D., Roiser, J. P., Dietrich, D. E., Bonnemann, C., Lanfermann, H., Emrich, H. M., \& Dillo, W. (2009). Understanding why patients with schizophrenia do not perceive the hollow-mask illusion using dynamic causal modelling. NeuroImage, 46(4), 1180-1186. https://doi.org/10.1016/j.neuroimage.2009.03.033

Drayson, Z. (2018). Direct perception and the predictive mind. Philosophical Studies, 175, 3145-3164. https://doi.org/10.1007/s11098-017-0999-x

Dretske, F. (1995). Naturalizing the mind. Cambridge, MA: The MIT Press.

Dretske, F. (2003). Experience as representation. Philosophical Issues, 13(1), 67-82. https://doi.org/10.1111/1533-6077.00005

Feldman, D. E. (2012). The spike-timing dependence of plasticity. Neuron, 75, 556-571. https://doi.org/10.1016/j.neuron.2012.08.001

Fish, W. (2009). Perception, hallucination, and illusion. Oxford: Oxford University Press.

Foulkes, D., \& Fleisher, S. (1975). Mental activity in relaxed wakefulness. Psychology, 84(1), 66-75. https://doi.org/10.1037/h0076164

Friston, K. J. (2003). Learning and inference in the brain. Neural Networks, 16(9), 1325-1352. https://doi.org/10.1016/j.neunet.2003.06.005

Friston, K. J. (2010). The free-energy principle: A unified brain theory? Nature Reviews Neuroscience, 11(2), 127-138. https://doi.org/10.1038/nrn2787

Friston, K. J., \& Stephan, K. E. (2007). Free-energy and the brain. Synthese, 159, 417-458. https://doi.org/10.1007/s11229-007-9237-y

Genone, J. (2016). Recent work on naïve realism. American Philosophical Quarterly, 53(1), 1-26. Retrieved from https://www.jstor.org/stable/44982080

Gregory, R. L. (1980). Perceptions as hypotheses. Philosophical Transactions of the Royal Society of London. B, Biological Sciences, 290(1038), 181-197. https://doi.org/10.1098/rstb.1980.0090

Hellie, B. (2014). Love in the time of cholera. In B. Brogaard (Ed.), Does perception have content? (pp. 241-261). Oxford: Oxford University Press.

Helmholtz, H. von. (2005). Treatise on physiological optics (Vol. 3; J. P. C. Southhall, Ed.). Mineola: Dover. (Original work published 1924)

Hohwy, J. (2013). The predictive mind. Oxford: Oxford University Press.

Hohwy, J. (2016). The self-evidencing brain. Noûs, 50(2), 259-285. https://doi.org/10.1111/nous.12062

Hume, D. (1993). An enquiry concerning human understanding (2nd ed.; E. Steinberg, Ed.). Indianapolis: Hackett Publishing Company. (Original work published 1777)

Hume, D. (2000). A treatise of human nature (D. F. Norton \& M. J. Norton, Eds.). Oxford: Clarendon Press. (Original work published 1739)

Jackson, F. (1977). Perception: A representative theory. Cambridge: Cambridge University Press.

Jackson, M. B. (2013). Recall of spatial patterns stored in a hippocampal slice by long-term potentiation. fournal of Neurophysiology, 110, 2511-2519. https://doi.org/10.1152/jn.00533.2013

Kensinger, E. A. (2009). Remembering the details: Effects of emotion. Emotion Review, 1(2), 99-113. https://doi.org/10.1177/1754073908100432

Kersten, D., \& Yuille, A. (2003). Bayesian models of object perception. Current Opinion in Neurobiology, 13(2), 150-158. https://doi.org/10.1016/S0959-4388(03)00042-4

Liu, X., Ramirez, S., Redondo, R. L., \& Tonegawa, S. (2014). Identification and manipulation of memory engram cells. Cold Spring Harbor Symposia on Quantitative Biology, 79, 59-65. https://doi.org/10.1101/sqb.2014.79.024901

Lycan, W. G. (2001). The case for phenomenal externalism. Philosophical Perspectives, 15, 17-35. https://doi.org/10.1111/0029-4624.35.s15.2

Martin, C. B., \& Deutscher, M. (1966). Remembering. Philosophical Review, 75(2), 161-196. https://doi.org/10.2307/2183082

Martin, M. G. F. (2001). Out of the past: Episodic recall as retained acquaintance. In C. Hoerl \& T. McCormack (Eds.), Time and memory (pp. 257-284). Oxford: Oxford University Press.

Martin, M. G. F. (2004). The limits of self-awareness. Philosophical Studies, 120(1-3), 37-89. https://doi.org/10.1023/B:PHIL.0000033751.66949.97

Barkasi, M., \& Rosen, M. G. (2020). Is mental time travel real time travel? Philosophy and the Mind Sciences, 1(1), 1. https://doi.org/10.33735/phimisci.2020.1.28

(c) (1) (c) The author(s). https://philosophymindscience.org ISSN: 2699-0369 
Mather, G. (2016). Foundations of sensation and perception (3rd ed.). New York: Psychology Press.

Matthen, M. (2005). Seeing, doing, and knowing: A philosophical theory of sense perception. Oxford: Oxford University Press. Matthen, M. (2010). Is memory preservation? Philosophical Studies, 148, 3-14. https://doi.org/10.1007/s11098-010-9501-8 Metzinger, T. (2009). The ego tunnel: The science of the mind and the myth of the self. New York: Basic Books.

Michaelian, K. (2011). Generative memory. Philosophical Psychology, 24(3), 323-342. https://doi.org/10.1080/09515089.2011.559623

Michaelian, K. (2016a). Confabulating, misremembering, relearning: The simulation theory of memory and unsuccessful remembering. Frontiers in Psychology, 25(1857), 1-13. https://doi.org/10.3389/fpsyg.2016.01857

Michaelian, K. (2016b). Mental time travel: Episodic memory and our knowledge of the personal past. Cambridge, MA: The MIT Press.

Moran, A. (2019). Naïve realism, seeing stars, and perceiving the past. Pacific Philosophical Quarterly, 100(1), 202-232. https://doi.org/10.1111/papq.12238

Nagel, T. (1974). What is it like to be a bat? Philosophical Review, 83, 435-450. https://doi.org/10.2307/2183914

Noë, A. (2004). Action in perception. Cambridge, MA: The MIT Press.

Parfit, D. (1971). Personal identity. The Philosophical Review, 80(1), 3-27. https://doi.org/10.2307/2184309

Perrin, D. (2016). Asymmetries in subjective time. In K. Michaelian, S. B. Klein, \& K. K. Szpunar (Eds.), Seeing the future: Theoretical perspectives on future-oriented mental time travel (pp. 39-61). https://doi.org/10.1093/acprof:oso/9780190241537.003.0003

Quillian, M. R. (1968). Semantic memory. In M. Minsky (Ed.), Semantic information processing (pp. 227-270). Cambridge, MA: The MIT Press.

Rao, R. P. N., \& Ballard, D. H. (1999). Predictive coding in the visual cortex: A functional interpretation of some extra-classical receptive-field effects. Nature Neuroscience, 2(1), 79-87. https://doi.org/10.1038/4580

Rice, H. J., \& Rubin, D. C. (2009). I can see it both ways: First- and third-person visual perspectives at retrieval. Consciousness and Cognition, 18(4), 877-890. https://doi.org/10.1016/j.concog.2009.07.004

Robins, S. K. (2019). Confabulation and constructive memory. Synthese, 196, 2135-2151. https://doi.org/10.1007/s11229-017-1315-1

Russell, B. (1997). The problems of philosophy. Oxford: Oxford University Press. (Original work published 1912)

Ryle, G. (1945). Knowing how and knowing that: The presidential address. Proceedings of the Aristotelian Society, 46, 1-16. https://doi.org/10.1093/aristotelian/46.1.1

Sant'Anna, A. (2020). The hybrid contents of memory. Synthese, 197, 1263-1290. https://doi.org/10.1007/s11229-018-1753-4

Sant'Anna, A., \& Michaelian, K. (2019). Thinking about events: A pragmatist account of the objects of episodic hypothetical thought. Review of Philosophy and Psychology, 10, 187-217. https://doi.org/10.1007/s13164-018-0391-6

Schacter, D. L., \& Addis, D. R. (2007). The cognitive neuroscience of constructive memory: Remembering the past and imagining the future. Philosophical Transactions of the Royal Society B: Biological Sciences, 362(1481), 773-786. https://doi.org/10.1098/rstb.2007.2087

Schechtman, M. (1994). The truth about memory. Philosophical Psychology, 7, 3-18. https://doi.org/10.1080/09515089408573107

Schechtman, M. (2011). Memory and identity. Philosophical Studies, 153(1), 65-79. https://doi.org/10.1007/s11098-010-9645-6

Schellenberg, S. (2011). Perceptual content defended. Noûs, 45(4), 714-750. https://doi.org/10.1111/j.1468-0068.2010.00791.x

Siegel, S. (2010). The contents of visual experience. Oxford: Oxford University Press.

Speaks, J. (2015). The phenomenal and the representational. Oxford: Oxford University Press.

Suddendorf, T., \& Corballis, M. C. (2007). The evolution of foresight: What is mental time travel, and is it unique to humans? Behavioral and Brain Sciences, 30, 299-351. https://doi.org/10.1017/S0140525X07001975

Sutton, J. (1998). Philosophy and memory traces: Descartes to connectionism. Cambridge: Cambridge University Press.

Sutton, J. (2003). Constructive memory and distributed cognition: Towards an interdisciplinary framework. In B. Kokinov \& W. Hirst (Eds.), Constructive memory (pp. 290-303). Sofia: New Bulgarian University.

Travis, C. S. (2004). The silence of the senses. Mind, 113(449), 57-94. https://doi.org/10.1093/mind/113.449.57

Tulving, E. (1972). Episodic and semantic memory. In E. Tulving \& W. Donaldson (Eds.), Organization of memory (pp. 381-403). New York: Academic Press.

Tulving, E. (1983). Elements of episodic memory. Oxford: Oxford University Press.

Barkasi, M., \& Rosen, M. G. (2020). Is mental time travel real time travel? Philosophy and the Mind Sciences, 1(1), 1. https://doi.org/10.33735/phimisci.2020.1.28

(c) () ( T) The author(s). https://philosophymindscience.org ISSN: 2699-0369 
Tulving, E. (2002). Episodic memory: From mind to brain. Annual Review of Psychology, 53, 1-25. https://doi.org/10.1146/annurev.psych.53.100901.135114

Tye, M. (1995). Ten problems of consciousness: A representational theory of the phenomenal mind. Cambridge, MA: The MIT Press.

Winograd, T. (1972). Understanding natural language. Cognitive Psychology, 3(1), 1-191. https://doi.org/10.1016/0010-0285(72)90002-3

Zylberberg, J., \& Strowbridge, B. W. (2017). Mechanisms of persistent activity in cortical circuits: Possible neural substrates for working memory. Annual Review of Neuroscience, 40, 603-627. https://doi.org/10.1146/annurev-neuro-070815-014006

\section{Open Access}

This article is distributed under the terms of the Creative Commons Attribution 4.0 International License (https://creativecommons.org/licenses/by/4.0/), which permits unrestricted use, distribution, and reproduction in any medium, as long as you give appropriate credit to the original author(s) and the source, provide a link to the Creative Commons license, and indicate if changes were made. 